\title{
Incremental Strategies for Suburban Densification
}

\section{Tegan Wardle}

Victoria University of Wellington, Wellington, New Zealand

wardletega@myvuw.ac.nz

\section{Guy Marriage}

Victoria University of Wellington, Wellington, New Zealand

guy.marriage@vuw.ac.nz

\begin{abstract}
Sprawling, low density development dominates and destroys natural landscapes and productive farm land at the edges of urban centres. Yet, suburbs continue to grow outwards, requiring continual development of green field sites to keep up with housing demand. Additionally, existing dwellings are demolished to make way for new developments with minimally increased density, creating waste in an industry that generates over $50 \%$ of New Zealand's landfill. In spite of this, New Zealanders' reported preferences for stand-alone dwellings on private sections and NIMBY attitude challenge higher density settlements, perceiving them as less safe, less visually appealing and less able to provide an enjoyable lifestyle. This research addresses the need for higher density living within the Wellington suburban context, while attempting to meet these challenges through the incremental implementation of accessory dwelling units that fit around existing dwellings. The implementation of this strategy has been tested within the Wellington suburb of Kilbirnie through the dimensional analysis of existing sites and the iterative design of accessory dwelling units. From this, possible new levels of density have been estimated within various areas of the suburb to investigate the feasibility of achieving higher density by adding small scale dwellings to front, side and back yard sites.
\end{abstract}

Keywords: Accessory dwelling units; suburban densification; incremental construction; New Zealand.

\section{INTRODUCTION}

\subsection{The problem}

Sprawling development dominates and destroys natural landscapes and productive farm land at the edges of urban centres, as well as increasing reliance on private vehicle transport and vehicle miles travelled (Dedek, 2014). Yet, in New Zealand, suburbs continue to grow outwards requiring the development of green field sites to keep up with population growth and the overwhelming demand for stand-alone housing compared to higher density alternatives (Bryson, 2017).

Historically, and still prevalent today, New Zealanders have aspired to the 'quarter-acre dream', desiring stand-alone housing on private land (Bryson, 2017). A 2017 survey found respondents to perceive higher density settlements as less safe, less visually appealing, less value for money, less able to provide a good sense of community and less able to provide an enjoyable lifestyle (Bryson, 2017). In addition to this, the study found NIMBYism as a challenge for higher density housing, with participants reporting objections to having new housing with increased density built on their street (Bryson, 2017).

Despite these attitudes, housing pressure has caused a surge in construction of medium density housing (Bryson, 2017), often achieved through the demolition and redevelopment of lower density sites (Gray Partners Ltd, 2014). The increased density of these sites must be weighed against the energy, resource and waste cost of demolition and redevelopment, contributing to an industry that is estimated to be responsible for $40 \%$ of energy use, 30\% of greenhouse gas emissions and 136 million tonnes of waste annually (Yung and Chan, 2012). In New Zealand this issue may be more significant, with evidence suggesting construction and demolition waste represents up to $50 \%$ of waste sent to landfills and almost all waste sent to cleanfills, totalling to approximately 1.7 million tonnes annually (REBRI, 2014).

\subsection{The proposed solution}

The sustainable development of cities must aim to meet present and immediate needs, without compromising the ability to meet changing and uncertain needs in the future (Coyle, 2011). Such needs are inclusive of environmental, economic, social and cultural aspects, requiring development strategies to consider the natural environments, resource use, economic vitality, community self-reliance, generational equity and individual wellbeing (Yung and Chan, 2012).

The usefulness of buildings within urban centres contributes to the amenity of public and reduces the need for peripheral, car related development (Dedek, 2014). Therefore, by redirecting growth inward, through densification rather than sprawl, centrally located neighbourhoods can be made more useful and desirable places to live (Dunham-Jones and Williamson, 2008). This can be achieved most successfully in underperforming areas where infrastructure is already in place, most 
significantly depending on proximity to public transport (Dunham-Jones and Williamson, 2008). Densification of such areas not only ensures accommodation of population growth, but also access to a desirable public realm, with a mix of uses within walking distance (Dunham-Jones and Williamson, 2008).

To address the issue of resistance to increased density, research into urban design has identified the importance of time as a dimension in design. Despite the inevitability of change in the urban environment, fast paced change can be distressing (Carmona et al., 2010). Alternatively, slow paced, incremental change is seen as comfortable and acceptable (Carmona et al., 2010). Change in the urban environment is therefore recommended to be moderated, avoiding comprehensive redevelopment, to prevent dislocation and preserve continuity with the past (Carmona et al., 2010).

Strategies to increase density should therefore fit around existing dwellings and be designed in a manner that allows for incremental increases in density over time. One way this may be achieved, which will be further explored by this research, is through the implementation of accessory dwelling units (ADUs) within existing residential sites. This will not only contribute to the coherence and familiarity of the suburb, but will also ensure minimal demolition waste is created to achieve higher density on already occupied sites within existing suburbs.

\section{METHOD}

The research analyses and compares existing planning rules within New Zealand to determine their current provision for increasing suburban density and the restrictions they pose for ADUs. Following this, a case study suburb within the Wellington region is selected, based on sustainable densification criteria from the literature reviewed. Through the use of Wellington City Council GIS data, the sites within this suburb are then analysed to determine common site typologies and their characteristics.

From the site typologies identified, a range of ADUs are designed based on iterative massing and plan experimentation to determine the approximate size and shape of sites needed. These site requirements are then used to test the feasibility of each site typology. From this analysis, the resulting density levels able to be achieved are estimated in dwelling units per hectare (du/ha) to determine the site typology able to provide the highest density through the addition of ADUs.

The design of ADU for the most successful site typology is then tested further on a range of test sites within the suburb. Analysis of resulting shading and sunlight access for the ADUs and surrounding existing dwellings is then done through the use of the software 3ds Max, to determine the impact of adding these dwellings to the existing sites.

\section{ANALYSIS OF EXISTING PLANNING RULES}

\subsection{Current provisions to address the densification of existing suburban areas}

The problem of unmet housing demand in New Zealand has been largely addressed with respect to land prices and mortgage access, rather than through investigation and implementation of alternative housing strategies (Saville-Smith et al., 2017). Strategies that utilise existing residential land, such as the implementation of ADUs, have therefore drawn little attention (Saville-Smith et al., 2017). In addition to this, little consistency in planning policies exists across jurisdictions and rules are reportedly poorly articulated, lacking coherent reasoning behind their objectives (Saville-Smith et al., 2017). Therefore, wide scale adoption of such strategies may be hindered rather than promoted by district plans.

The addition of new builds on existing residential sites do not have title requirements, differing from site subdivision, however, they must still conform to district planning rules (Saville-Smith et al., 2017). Of New Zealand's 67 local Authorities, 44 permit the addition of a residential dwelling on an already built site, while another 7 permit the addition of a dwelling only for the purpose of housing family members (Saville-Smith et al., 2017). Within each Authority, rules relating to the addition of an ADU typically vary according to zone, often depending on the existing character and density of the area (Saville-Smith et al., 2017). Variation and implications of these rules have been examined further through the comparison of the Auckland Unitary Plan and the Wellington District Plan (Table 1).

\subsection{Comparison of the Auckland Unitary Plan and the Wellington District Plan}

Both Auckland and Wellington planning objectives are similar in their aim to achieve higher residential intensities within already developed areas that are close to existing centres, public amenities and public transport networks. However, despite these aims, both Authorities still additionally address growth through provisions for greenfield development of rezoned land for new suburbs.

Both Authorities also aim to ensure that development conforms to the existing suburban character of existing areas, respecting existing built form and current levels of property amenity. Rules are most restrictive in areas with lower existing density, aiming to maintain and enhance the values of residential neighbourhoods and their spacious lot sizes, informed by past 
development strategies. One exception to this is the Wellington District Plan provision for 'Medium Density Residential Areas' which aims to achieve comprehensive redevelopment that results in moderate to significant increases in residential density without a need to maintain the existing character of the area.

Table 1: Comparison of the Auckland Unitary Plan and Wellington District Plan rules for ADUs.

\begin{tabular}{|c|c|c|c|c|c|}
\hline & $\begin{array}{l}\text { Number of } \\
\text { dwellings } \\
\text { permitted }\end{array}$ & $\begin{array}{l}\text { Max site } \\
\text { coverage }\end{array}$ & $\begin{array}{l}\text { Max } \\
\text { height } \\
(\mathrm{m})\end{array}$ & $\begin{array}{l}\text { Other dwelling size } \\
\text { restrictions }\end{array}$ & $\begin{array}{l}\text { Minimum outdoor space } \\
\text { provision per dwelling } \\
\left(\mathrm{m}^{2}\right)\end{array}$ \\
\hline \multicolumn{6}{|l|}{ Auckland } \\
\hline Residential - Single House Zone & $\begin{array}{l}1+1 \text { minor } \\
\text { dwelling }\end{array}$ & $35 \%$ & 8 & $\begin{array}{c}\text { Minor dwelling must not } \\
\text { exceed 65m2 }\end{array}$ & $\begin{array}{l}\text { Minor dwellings: } 5 \text { for } \\
\text { one bed, } 8 \text { for two or } \\
\text { more bed }\end{array}$ \\
\hline $\begin{array}{l}\text { Residential - Mixed Housing } \\
\text { Suburban Zone }\end{array}$ & 2 & $40 \%$ & 8 & $\begin{array}{l}\text { Minimum dwelling size } \\
\text { of } 30 \mathrm{~m}^{2}\end{array}$ & 20 \\
\hline \multicolumn{6}{|l|}{ Wellington } \\
\hline Outer Residential Area & 2 & $35 \%$ & 8 & $\begin{array}{l}\text { Maximum height of an } \\
\text { Infill Household Unit is } \\
4.5-6 \mathrm{~m}\end{array}$ & 50 \\
\hline Inner Residential Area & 2 & $50 \%$ & 10 & none & 35 (20 must be private) \\
\hline
\end{tabular}

Rules for ADUs are most restrictive in Auckland's Single House Zone and Wellington's Outer Residential Area, likely due the existing lower densities of these areas. In these areas, maximum site coverages are low, restricting the footprint of dwellings and promoting underutilisation of sites. The size of a second dwelling sited within these areas is also regulated, restricted by floor area in Auckland and by height in Wellington. The minimum provision for outdoor space is also high in Wellington's Outer Residential Area, promoting past suburban ideals of large lot sizes. Outdoor space requirements are however minimised in Auckland for 'minor dwellings', recognising a difference in amenity provision for ADUs.

In the higher density suburban zones, classified as the Mixed Housing Suburban Zone in Auckland and the Inner Residential Area in Wellington, rules are less restrictive. The Wellington District Plan allows larger heights and site coverages, while posing no additional size restraints on dwellings. However, minimum outdoor space provision is greater in Wellington, with additional requirements for minimum private outdoor space, rather than allowing this to be shared between units. This again reinforces past suburban ideals for large amounts of private outdoor space.

\section{SELECTION OF A SITE SUITABLE FOR DENSIFICATION}

Kilbirnie, a suburb in the outer residential area of Wellington City, has been selected as a case study for this research due to the area exhibiting a range of characteristics that are likely to support densification, following recommendations by DunhamJones and Williamson (2008). These include:

- Public transport infrastructure; Kilbirnie is located on a key transport route from the CBD to the airport, planned for investment and upgrade of public transport and roading as part of the Wellington City Council (WCC) 10 year plan (Macleod, 2014).

- A mix of uses in walking distance; Kilbirnie contains a central shopping area, schools, a number of sports and recreational facilities, a large area of public park land and borders the town belt.

- The ability to become an economic engine and destination: Kilbirnie has a large proportion of commercially zoned land located at its centre.

Due to its location, existing infrastructure and amenity, a portion of the residential area within Kilbirnie was zoned by the WCC in 2010 for medium density housing (Gray Partners Ltd, 2014). However, despite this zoning change, very little development has taken place since then (Gray Partners Ltd, 2014). Financial feasibility studies have attributed this largely to the small scale of land parcels available, requiring developers to take a very long term stance to development, needing to acquire multiple adjoining lots as they become available for purchase to receive any substantial profit margin (Gray Partners $L t d, 2014)$. Due to this, the smaller scale implementation of ADUs on an individual plot scale may provide a more financially feasible solution to increasing density in the suburb. 


\subsection{Common site typologies identified}

Three common site typologies have been observed within a range of residential areas within Kilbirnie (Figure 1). These consist of:

- Front yards, located within the front setback between existing houses and property boundary facing the street.

- Side yards, located within the strip of land between neighbouring dwellings (measured between dwellings, across site boundaries)

- Back yards, located within the land behind existing dwellings, within property boundaries

Much of this land is underutilised, often created by planning rules within the district plan mandating minimum front and site yards, as well as maximum site coverage. Potential use of this land in achieving higher density housing without reduction in quality or amenity follows recommendations by Marriage (2014). This calls for the relaxation or deletion of restrictive, and perhaps outdated, District Plan mandates in New Zealand suburbs that create low density suburbs with considerable wastage of land.

\section{INITIAL DESIGN OF ADUS}

Experimentation through iterative plan and massing studies has been undertaken to determine a minimum sized one or two bedroom dwelling, including kitchen, bathroom and living space, suitable for each site typology. Successful designs (Figure 1) have been selected based on size efficiency, integration of outdoor space and the privacy of window outlook for the ADUs and existing dwellings.

\subsection{Design of building form and fenestration for privacy and amenity}

Due to current preferences for stand-alone housing with private outdoor space (Bryson, 2017), maintaining the privacy of existing dwellings and their outdoor space, as well as providing privacy for the ADUs has been considered as an important issue, driving the development of form and fenestration.

For front yard dwellings, amenity of access to the existing dwelling is maintained by minimising the width of the ADU to ensure at least $2 \mathrm{~m}$ of space along the side of the ADU to allow access to the existing dwelling's front door. Privacy issues for the ADU are minimised by disallowing windows on the street facing side of the building and by creating an L-shaped form to frame the outdoor space and set back the windows from the existing dwelling.

For side yard dwellings, privacy for the ADU is created by restricting windows to the front and rear of the building only. This ensures no windows along the length of the dwelling that may look into the side windows of existing dwellings. The long form may also work to improve the privacy of existing dwellings, preventing overlooking of outdoor space across the site boundary by creating a boundary wall.

For back yard dwellings, the form and plan layout allows the ADU to wrap around the site and provide private courtyard spaces. Openings are therefore only created on walls looking into these courtyards and disallowed on walls bordering property boundaries, or the back of the existing dwelling. Garden walls are employed above eye height around these courtyards to provide further privacy. 

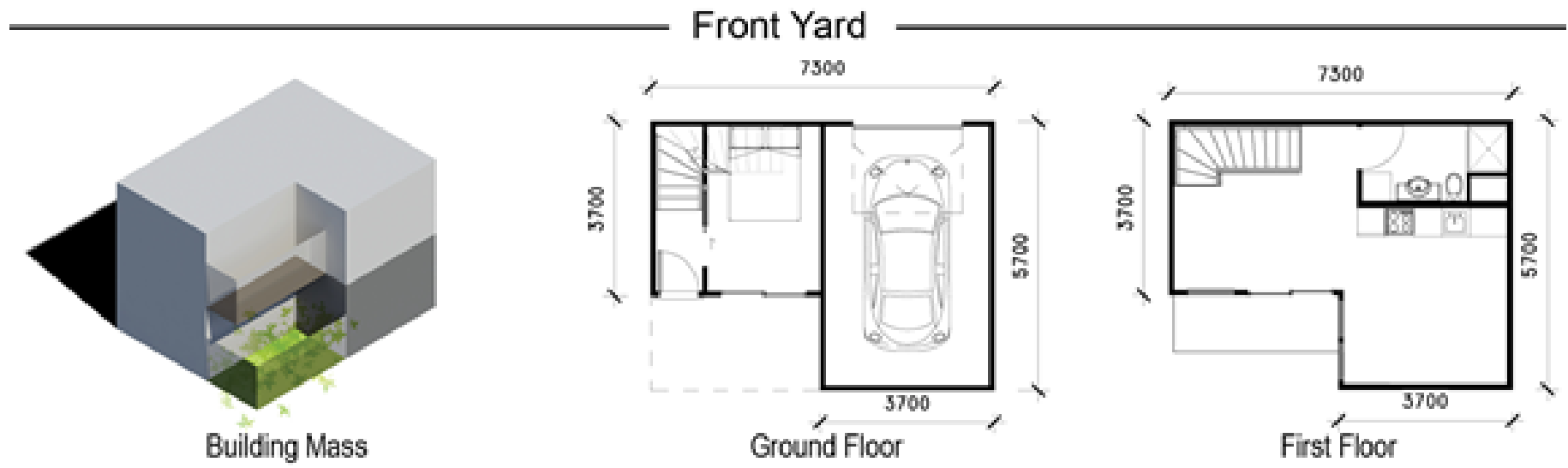

\section{Side Yard}

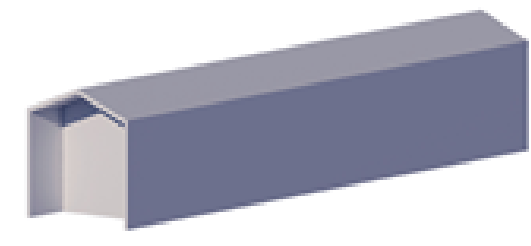

Building Mass

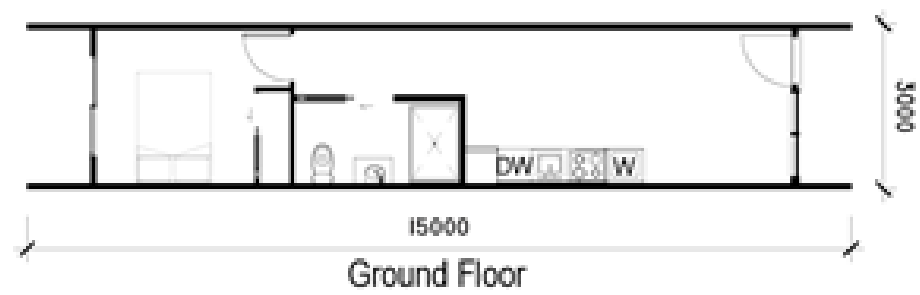

Back Yard

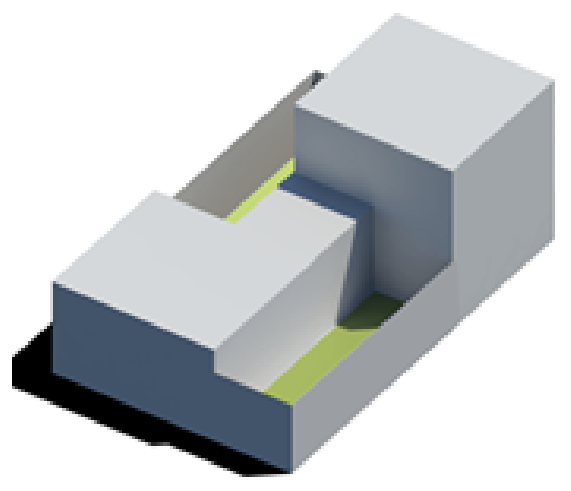

Building Mass

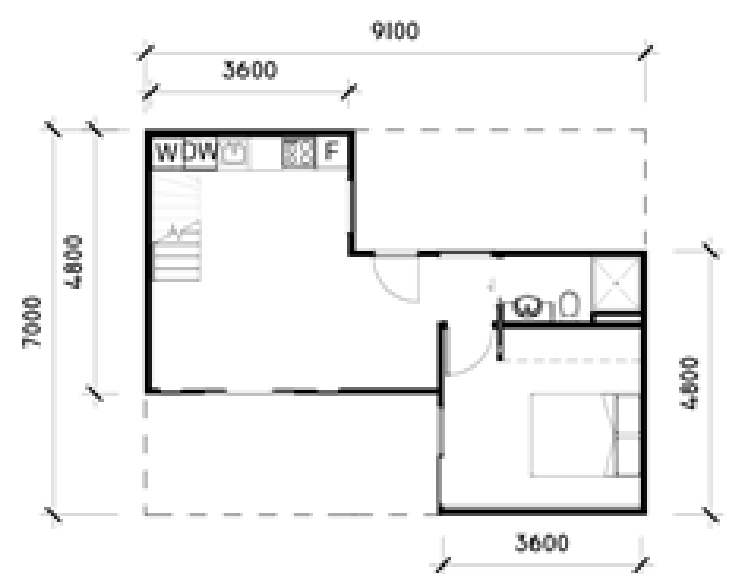

Ground Floor

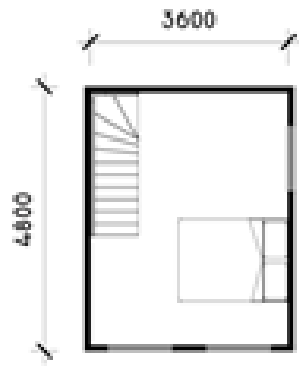

First Floor

Figure 1: Initial designs of ADUs for front, side and back yard sites. (source: author)

The resulting minimum site dimensions for these dwellings for each site type as follows:

- Front yards: $5300 \mathrm{~mm} \times 9300 \mathrm{~mm}$

- Side yards: $3000 \mathrm{~mm} \times 15000 \mathrm{~mm}$

- Back yards: $7000 \mathrm{~mm} \times 9100 \mathrm{~mm}$

\section{DENSITY ANALYSIS OF AVAILABLE SITES}

The levels of density able to be achieved through the addition of ADUs on the identified site typologies have been estimated for a range of areas within the suburb, each with varying initial densities (Table 2). This has been done based on the available site sizes and shapes around existing dwellings, informed by the initial ADU plan and massing studies. Due to the varying configuration of sites and openings of existing dwellings for sunlight access, some of these sites are more feasible than others. 
Table 2: Levels of density achieved across the sites investigated.

\begin{tabular}{|c|c|c|c|c|c|c|}
\hline & $\begin{array}{l}\text { Average } \\
\text { width (m) }\end{array}$ & $\begin{array}{l}\text { Average } \\
\text { length (m) }\end{array}$ & Topography & $\begin{array}{c}\text { Number of } \\
\text { suitable sites }\end{array}$ & Density (du/ha) & $\begin{array}{l}\text { Density } \\
\text { increase }\end{array}$ \\
\hline Area 1 & & & & & Existing: 24.2 & \\
\hline Front yards & 15.3 & 7.4 & Flat & 31 & 33.6 & $39 \%$ \\
\hline Side yards & 4.2 & 40.3 & Flat & 25 & 31.8 & $31 \%$ \\
\hline Back yards & 15.3 & 16.3 & Flat & 22 & 30.9 & $28 \%$ \\
\hline Area 2 & & & & & Existing: 31.5 & \\
\hline Front yards & 9.1 & 4.7 & Flat & 3 & 33.6 & $7 \%$ \\
\hline Side yards & 1.5 & 34.9 & Flat & 1 & 32.2 & $2 \%$ \\
\hline Back yards & 9.1 & 12.0 & Flat & 46 & 63.0 & $100 \%$ \\
\hline Area 3 & & & & & Existing: 14.8 & \\
\hline Front yards & 13.5 & 11.0 & Flat-sloped & 28 & 26.7 & $80 \%$ \\
\hline Side yards & 4.9 & 41.5 & Sloped-steep & 17 & 22.0 & $48 \%$ \\
\hline Back yards & 14.5 & 16.7 & Sloped-steep & 30 & 27.6 & $86 \%$ \\
\hline
\end{tabular}

\subsection{Front yards}

Front yard sites provide the most promise in terms of access, both in terms of access to the dwelling from the street and access to daylight. These benefits to the ADU however are likely in most cases to directly reduce these benefits for the existing dwelling on site, restricting their access from the street, and on smaller sites, reducing their daylight access. Despite this, a large number of the front yard sites in Kilbirnie already contain garage structures, showing acceptability for building on these sites. These negative impacts would also be limited to the immediate site, with minimal impact on neighbouring properties. Dwellings on these sites would also provide the opportunity to make use of underutilised land, typically unused as recreational yard or garden space due to its proximity to the street. This proximity to the existing road may pose issues for the ADU in terms of privacy and acoustics, however, this may be mediated through careful design of openings.

The use of front yards has achieved increases in density in both Area 1 and 3 (Table 2). This has been most successful in area 3 where initial density was very low due to large section sizes allowing existing dwellings to have large setbacks from the street. Front yard sites have been largely unsuccessful in Area 2 due to the small distance of front yard setback between existing dwellings and the road in this area. Overall, the width of the site between neighbouring properties has typically been sufficient, causing the length of the site between the existing dwelling and the road to limit site usability.

\subsection{Side yards}

Side yard sites provide the opportunity to minimise impact on existing urban patterns, impacting neither existing street setback patterns, nor the openness of existing back yards. Side yards are easily accessible from the street and are currently the least utilised sites, lacking the size or privacy for garden or recreational space. However, these sites are often used on one side of each property for driveway access to back yard garages which may limit building on these sites. These sites are the least available within the suburb and are typically only narrow strips, requiring close proximity to existing dwellings and restricting the possible width of ADUs. This would also limit daylight access to the ADU and the existing dwellings, although window openings are already minimal along the sides of existing dwellings. Another limitation of these sites would be a common requirement to locate the dwelling over the boundary of two existing properties to gain sufficient land width.

The use of side yards has been moderately successful in increasing density in both Area 1 and 3 (Table 2), limited by the large proportion of existing dwellings located too close together to allow another dwelling to fit between. Area 3 typically provides the most width of these sites, however the steepness of many of these sites provide a challenge for long, narrow dwellings. Side yard sites have been unsuccessful in Area 2 due to very narrow side yards between existing dwellings, wide enough only for vehicle or pedestrian access to the back yard. Overall, length of these has not been an issue.

\subsection{Back yards}

Back yard sites present the most promising opportunity in terms of size and distance from existing dwellings, minimising possible negative impacts on daylight access and privacy for the ADUs and the existing dwellings. However, despite having the least impact on the site the ADU is added to, placing the structure close to property boundaries may cause this typology to have the greatest impact on neighbours' properties and receive objection. Back yards are also the most currently utilised areas of land, providing space for recreation, gardens, garages and storage structures, especially in Area 1 and 2. In addition to this, private back yards reportedly provide a key amenity that makes lower density suburban living desirable (Bryson, 
2017). Access to these sites is also the least convenient, requiring thoroughfare past the existing dwelling, although, this may be somewhat mediated by the prevalence of existing driveways along the side yards of most properties.

Back yard sites have achieved the highest levels of density overall, creating the largest increases in density in both Area 2 and 3 (Table 2). A smaller increase in density can be seen for Area 1, limited not by site suitability, but by the already existing implementation of ADUs and site subdivisions that utilise back yard sites in this area. Similarly to front yard sites, the width between boundaries is not typically an issue, but rather the length of the site between the existing dwelling and the back site boundary.

Therefore, back yard sites have been selected as the most successful site typology within the case study suburb of Kilbirnie.

\section{TESTING OF BACK YARD ADUS}

The feasibility and suitability of the back yard ADU design has been tested and further developed through siting the dwellings on four neighbouring properties within three areas of Kilbirnie. Sunlight access and the impacts of shading have been analysed using the software 3ds Max to determine the success of the design, as well as the resulting impact on the existing sites and dwellings (Figure 2).

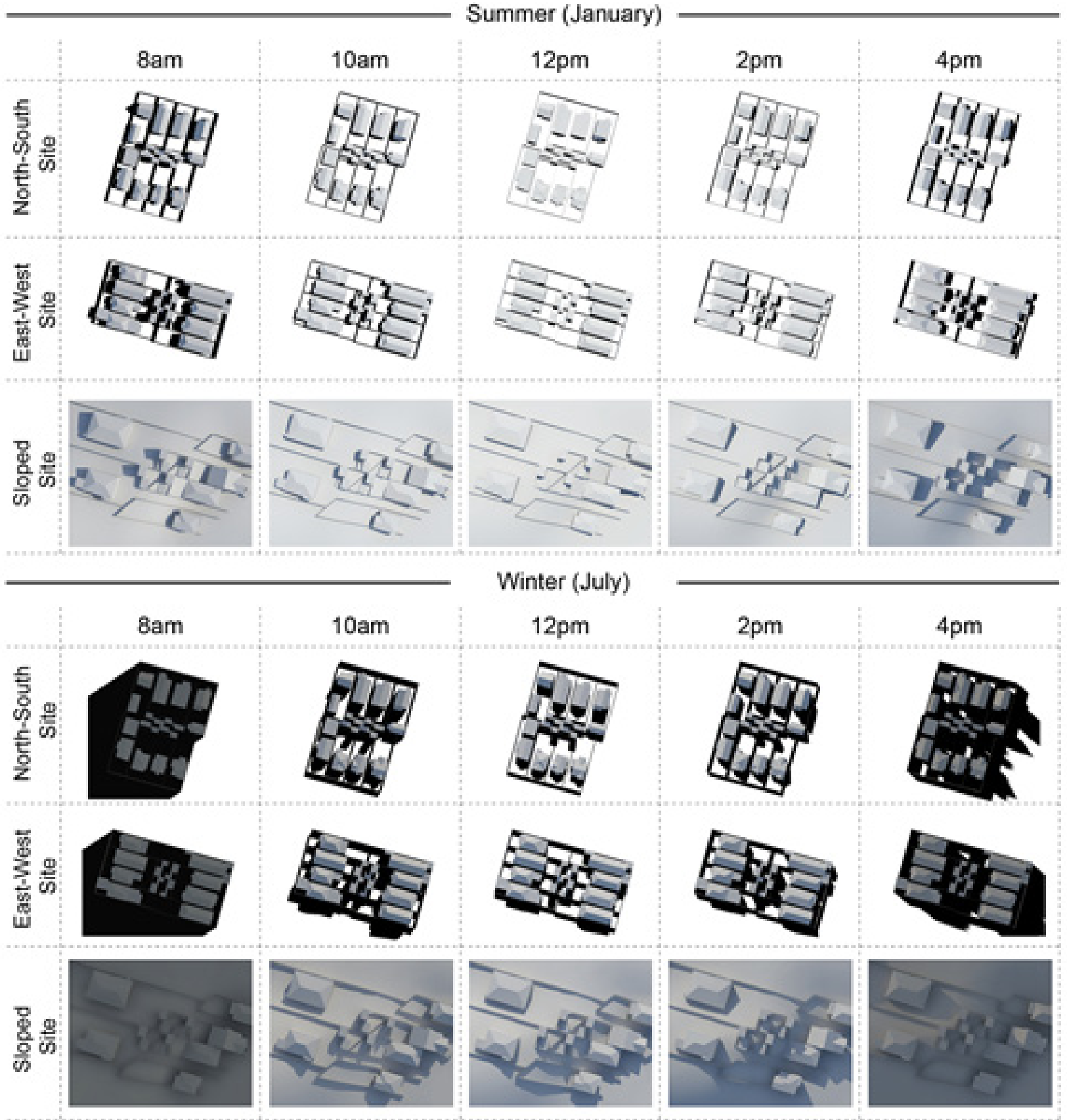

Figure 2: Sunlight analysis of ADUs implemented in three sites within Kilbirnie. (source: author) 
Sunlight studies show the implementation of the back yard ADU design is least successful on the North-South running backyards, as Northern sited ADUs shade the ADUs on the neighbouring back yards behind them considerably. These also have the greatest impact on shading the yards of the existing dwellings. East-West running sites are more successful, allowing sun into the courtyards of the ADUs in both summer and winter. These also have a lower impact on shading in the yards of the existing dwellings. The sloped site is the most successful, utilising the topography to step dwellings down the slope to allow maximum sunlight access to the ADUs and their courtyards. Overall, the ADUs on all sites have very little impact on the sunlight access of existing dwellings.

\section{CONCLUSION}

The implementation of ADUs has been explored within the suburb of Kilbirnie to determine the levels of density able to be achieved through the incremental addition of units, while respecting existing dwellings. This attempts to address the need for higher density living, while meeting the challenge of construction and demolition waste, as well as New Zealanders' preferences for low density, suburban living with private outdoor space.

Available pieces of land around existing dwellings, characterised as front, side and back yards, all present significant limitations with respect to access, daylight and privacy. However, through sensitive architectural design, ADUs could better utilise this land to increase density without compromising quality of living within the suburb. The sizes of these fragmented sites have provided the biggest challenge, often insufficient for the minimum floor area needed for an ADU.

Siting ADUs on back yard sites has been found to be most promising, allowing sufficient land to site two bedroom ADUs with private courtyards. Sunlight analysis has found siting of these dwellings to be most successful on East-West running blocks of housing, as well as on sloped sites, to provide the most sunlight access year round to the ADUs, as well as the yards of existing dwellings.

Further research will look at the development of construction strategies to implement these ADUs on existing sites, exploring the possibilities of prefabrication and addressing issues of site access.

\section{References}

Auckland Council (2018) The Auckland Unitary Plan Operative in part, Auckland Council, Auckland.

Bryson, K. (2017) The New Zealand Housing Preferences Survey: Attitudes towards medium-density housing, BRANZ Ltd, Judgeford.

Carmona, M., Heath, T., Oc, T. and Tiesdell, S. (2010) Public Places - Urban Spaces : The Dimensions of Urban Design, Architectural Press, Boston.

Coyle, S. J. (2011) Sustainable and resilient communities: A comprehensive action plan for towns, cities, and regions, ed., John Wiley \& Sons.

Dedek, P. B. (2014) Historic Preservation for Designers, ed., Bloomsbury Publishing Inc, New York.

Dunham-Jones, E. and Williamson, J. (2008) Retrofitting suburbia: urban design solutions for redesigning suburbs, ed., John Wiley \& Sons.

Gray Partners Ltd (2014) Commercial Drivers for Medium-Density Residential Development in Selected Wellington Suburbs Wellington City Council, Wellington.

Macleod, A. (2014) Wellington City Housing and Residential Growth Study: Final Planning Assessment and Recommendations, Wellington City Council, Wellington.

Marriage, G. (2014) Pavlova paradise and the curse of the side yard, Building A Better New Zealand, 360-365.

REBRI (2014) Waste Reduction - CONSTRUCTION, REBRI.

Saville-Smith, K., Saville-Smith, N. and Fraser, R. (2017) ADU Potential: Have we the potential to use our existing housing stock of homes to create a bigger stock of affordable, fit for purpose homes?,BBHTC:SRA - The Architecture of Decision Making, CRESA.

Wellington City Council (2018) The Wellington City District Plan, Wellington City Council, Wellington.

Yung, E. H. K. and Chan, E. H. W. (2012) Implementation challenges to the adaptive reuse of heritage buildings: Towards the goals of sustainable, low carbon cities, Habitat International Volume 36, Issue 3, 352-361. 